\title{
Study of maternal and perinatal outcome in abruptio placentae
}

\author{
Krupa Patel, Jaydeep Bhatu*, Swati Patel
}

Department of Obstetrics and Gynecology, GMERS Medical College and Hospital, Sola, Ahmedabad, Gujarat, India

Received: 08 March 2020

Accepted: 01 April 2020

\section{*Correspondence: \\ Dr. Jaydeep Bhatu, \\ E-mail: bhatujaydeep@gmail.com}

Copyright: () the author(s), publisher and licensee Medip Academy. This is an open-access article distributed under the terms of the Creative Commons Attribution Non-Commercial License, which permits unrestricted non-commercial use, distribution, and reproduction in any medium, provided the original work is properly cited.

\begin{abstract}
Background: Abruptio placentae is very frequently seen in our population. Few studies have reported maternal and fetal morbidity and mortality associated with this condition. No work has been done on abruptio placentae in our setup. The data generated will help to improve maternal and fetal morbidity and mortality by planning prompt management of future cases of placental abruption. Objective of this study was to study possible etiological factors of abruptio placentae, analyse maternal outcome, perinatal outcome in the form of maternal morbidity and mortality and discuss possible preventive measures and future management option

Methods: The retrospective observational study it was included all cases presenting with ante partum haemorrhage during the study period. Subjects selected for the study were all cases diagnosed as having abruptio placentae. All other causes of APH like placenta previa and other extraplacental causes were excluded.

Results: In the present study incidence of abruptio placentae is higher in $25-30$ year that were $42.5 \%$ and more in $2^{\text {nd }}$ gravida patient. PIH was accounting for $50 \%$, most of the patients $(95 \%)$ were anaemic at admission and majority of them required blood transfusion.one maternal mortality $(2.5 \%)$ occurred, perinatal mortality was $75 \%$.

Conclusions: Abruptio placentae serious condition with manifestation of significant maternal and perinatal morbidity and mortality. Complications can be reduced by provisional antenatal care to every woman and with improvement in medical facilities, availability of blood transfusion, proper management of shock. With liberalization of caesarean section, the rate of maternal morbidity and mortality is gradually on the decline.
\end{abstract}

Keywords: Abruptio placenta, Bleeding per vaginum, Maternal morbidity, Maternal mortality, Perinatal mortality, Placenta previa

\section{INTRODUCTION}

Placental abruption is the most common cause of antepartum haemorrhage and is defined as premature separation of normally implanted placenta. ${ }^{1}$ Placental abruption occurs when there is a compromise of the vascular structures supporting the placenta. In other words, the vascular networks connecting the uterine lining and the maternal side of the placenta are torn away. These vascular structures deliver oxygen and nutrients to the fetus. Disruption of the vascular network may occur when the vascular structures are compromised because of hypertension or substance use or by conditions that causes stretching the uterus.
The uterus is a muscle and is elastic whereas the placenta is less elastic than the uterus. Therefore, when the uterine tissue stretches suddenly, the placenta remains stable and the vascular structure connecting the uterine wall to the placenta tear away. ${ }^{2,3}$ Risk factor can be thought of in four groups: health history, past obstetrical events, current pregnancy, and unexpected trauma. Factors that increase the risk of placental abruption includes smoking, cocaine use during pregnancy, maternal age over 35 years, hypertension, and placental abruption in a prior pregnancy.

Abruptio placentae is a major cause of maternal and perinatal morbidity and mortality. ${ }^{4}$ Maternal 
complications include haemorrhagic shock, disseminated intravascular coagulation, renal failure, ischemic necrosis of distal organs e.g. Hepatic, adrenal and pituitary, uterine apoplexy or Couvelaire uterus leading to postpartum haemorrhage.

Fetal complications include hypoxia, anaemia, growth restriction, prematurity, neurodevelopmental problems and fetal death. ${ }^{4,5}$ Abruptio placentae is very frequently seen in this study population, however local work on this important condition of pregnancy is very sparse.

Few studies have reported maternal and fetal morbidity and mortality associated with this condition. No work has been done on abruptio placentae in this study setup. This study was undertaken to observe the fetal and maternal outcome of abruptio placentae in sola civil hospital Ahmedabad. The data generated will help to improve maternal and fetal morbidity and mortality by planning prompt management of future cases of placental abruption.

\section{Aims and objectives}

- To study possible etiological factors of abruptio placentae

- To analyse maternal outcome in the form of maternal morbidity and mortality

- To study perinatal outcome in the form of mortality and morbidity

- To discuss possible preventive measures and future management option.

\section{METHODS}

The retrospective observational study was carried out at the GMERS Medical College and civil Hospital, Sola, Sola Civil Hospital has 4700 deliveries per year. The study was carried out for a period of one year from January 2019 to June 2019.

The study population included all cases presenting with ante partum haemorrhage to the department of obstetrics and gynecology during the study period. Subjects selected for the study were all cases diagnosed as having abruptio placentae.

All other causes of APH like placenta previa and other extraplacental causes were excluded.

All study subjects underwent a complete obstetrical clinical workup including history, general physical examination, abdominal and pelvic examination. Relevant investigations such as laboratory tests and imaging were performed.

Patients were managed according to maternal and fetal condition. Any maternal and / or fetal complications were noted and recorded.

\section{Statistical analysis}

All data were collected on predesigned proformas and entered into the computer program SPSS version 10 for analysis. Statistical method analysis were quantitative variables were compared using independent t-test/MannWhitney test and observational analysis with inferential statistics method.

\section{RESULTS}

Table 1 shows that Most of the abruptio placenta cases were between 26 to 30 years $42.5 \%$. Next most common age group were between 20 to 25 years. Least incidence was seen among the age group $<20$ years.

Table 1: Age wise distribution.

\begin{tabular}{|lll|}
\hline Age & No. of cases (40) & Percentage \\
\hline$<20$ & 3 & $7.5 \%$ \\
\hline $20-25$ & 11 & $27.5 \%$ \\
\hline $26-30$ & 17 & $42.5 \%$ \\
\hline$>30$ & 9 & $22.5 \%$ \\
\hline
\end{tabular}

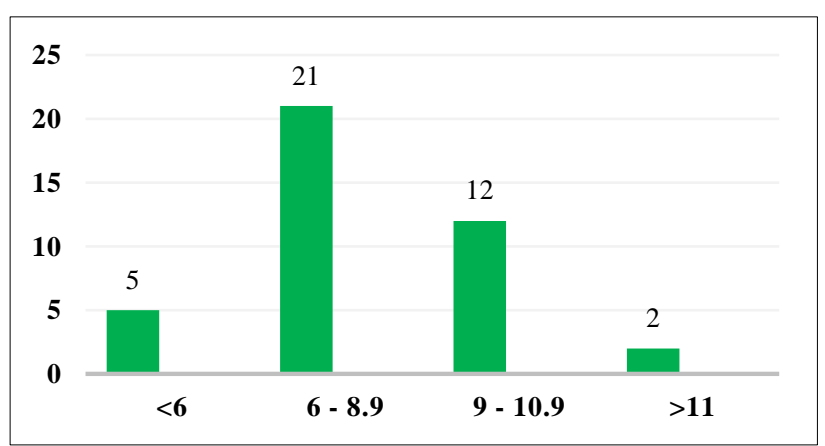

Figure 1: $\mathrm{Hb}(\mathrm{gm} \%)$ at the time of admission.

Figure 1 shows that $\mathrm{Hb}(\mathrm{gm} \%)$ at the time of admission which was moderate anaemia in most of the women.

Table 2: Parity wise distribution.

\begin{tabular}{|lll|}
\hline Parity & No. of cases $(\mathbf{n = 4 0})$ & Percentage \\
\hline Primigravida & 8 & $20 \%$ \\
\hline $2^{\text {nd }}$ gravida & 12 & $30 \%$ \\
\hline $3^{\text {rd }}$ gravida & 9 & $22.5 \%$ \\
\hline $4^{\text {th }}$ gravida & 4 & $10 \%$ \\
\hline Grand multigravida & 7 & $17.5 \%$ \\
\hline
\end{tabular}

Table 2 shows that maximum number of abruptio placenta cases were $2^{\text {nd }}$ gravida. Incidence of abruption was high in multiparous women and mainly abruption was seen in term pregnancy

Table 3 shows that in the present study PIH were most common risk factor of the abruptio placentae accounting for 22 cases out of 40 cases, other risk factors were 
multiparity, advanced maternal age, trauma, multifetal gestation previous $\mathrm{H} / \mathrm{O}$ abruptio, etc.

Table 3: Distribution of cases according to risk factors.

\begin{tabular}{|ll|}
\hline Risk factors & No. of cases $(\mathbf{n}=\mathbf{4 0})$ \\
\hline PIH & 20 \\
\hline Trauma & 1 \\
\hline Multifetal gestation & 1 \\
\hline Past history of APH & 3 \\
\hline Advance maternal age & 4 \\
\hline Unexplained & 11 \\
\hline
\end{tabular}

Table 4: Perinatal outcome in abruptio placentae.

\begin{tabular}{|lll|}
\hline Fetal outcome & No. of cases & Percentage \\
\hline Live birth & 15 & $37.5 \%$ \\
\hline Intrauterine death & 25 & $62.5 \%$ \\
\hline
\end{tabular}

Table 4 shows that $37.5 \%$ had live birth. $62.5 \%$ had still born. Among them 5 died in early neonatal period due to prematurity. Fetal complications included hypoxia, anemia, growth restriction, prematurity, neurodevelopmental problems, prematurity and fetal death.

Table 5: Mode of delivery in abruptio placentae.

\begin{tabular}{|lll|}
\hline Mode of delivery & No. of cases & Percentage \\
\hline Normal delivery & 24 & $60 \%$ \\
\hline Caesarean section & 16 & $40 \%$ \\
\hline
\end{tabular}

Table 6: Number of cases with complication with abruptio placentae.

\begin{tabular}{|ll|}
\hline Complication & No. of cases \\
\hline Postpartum haemorrhage & 5 \\
\hline AKI & 7 \\
\hline DIC & 4 \\
\hline Pulmonary oedema & 5 \\
\hline Shock & 3 \\
\hline Wound gap & 2 \\
\hline HDU admission & 24 \\
\hline Hysterectomy & 1 \\
\hline Ventilatory support & 2 \\
\hline Maternal mortality & 1 \\
\hline
\end{tabular}

Table 5 shows that mode of delivery almost $40 \%$ as caesarean. Table 6 shows that in the present study, pregnant women with abruptio placentae were at higher risk for developing complication like PPH (12.5\%), DIC (10\%), AKI (17.5\%), Shock (7.5\%) wound gap (5\%) and mortality in $2.5 \%$.

Table 7 shows that in the present study 30 cases of abruptio placentae required blood transfusion and 14 cases required FFP transfusion, 13 cases required cryoprecipitates transfusion, 9 cases required PRC transfusion.

Table 7: Blood product requirements.

\begin{tabular}{|lllll|}
\hline $\begin{array}{l}\text { Blood } \\
\text { component* }\end{array}$ & PCV & FFP & Cryoprecipitate & PRC \\
\hline No of cases & 30 & 14 & 13 & 9 \\
\hline
\end{tabular}

\section{DISCUSSION}

This is a retrospective study of 40 cases of abruptio placentae at study institute during the period of $1^{\text {st }}$ January 2019 to $30^{\text {th }}$ June 2019.

Overall incidence of abruptio placentae in this study is $1.7 \%$ as Sola civil has yearly 4700 deliveries. In the present study, most of the patients $(95 \%)$ anaemic at the time of admission and majority of them required blood transfusion (Figure 1). In the present study, incidence of abruptio placentae is higher in the age group of 26-30 year that were $42.5 \%$ (Table 1) and more in $2^{\text {nd }}$ gravida patient in the present study (Table 2). In the present study PIH was most common risk factor of the abruptio placentae accounting for $50 \%$ of cases (Table 3 ).

In the present study, perinatal mortality was $62.5 \%$ IUD and $12.5 \%$ live birth. Such a high rate was due to IUD which had more occurred in cases of abruptio placentae leads to poor prognosis as there is late presentation of the patient to the hospital, during which time the disease progress to an advanced stage (Table 4).

In the present study, one maternal mortality (2.5\%) occurred (Table 6). On account of complication like PPH and DIC, AKI patients needed to be transfused PCV/FFP/PRC/Cryoprecipitates (Table 7).

Most cases of abruptio placentae were diagnosed clinically; however, USG was performed in almost all the cases to know the size of clot and to decide further management. So, overall maternal outcome (97.5\%) was good in present study due to proper obstetric intrapartum and post-partum care, availability of wide range of antibiotics and blood components transfusion at this institute.

The present study clearly shows the importance of timely diagnosis and expert management by experienced clinician at all levels will help in improving maternal and foetal outcome in cases of abruptio placentae. Placental abruption is one of the serious complications of pregnancy, as it causes both poor maternal and fetal morbidity and mortality. The incidence of abruptio placenta was $1.7 \%$ in this study, which is somewhat near to study by Wasnik SK. ${ }^{6}$

The signs and symptoms of abruptio placenta vary depending upon the severity of bleeding, the degree of 
separation of the placenta and parity. Abruption can occur at any trimester in pregnancy but mostly it occurs at 32-36 weeks of pregnancy and in present study most commonly seen in second gravidas incidence in primigravida somewhat lower. ${ }^{7,8}$

\section{CONCLUSION}

In this study setup, frequency of abruptio placenta is comparable with local and international literature. Abruptio placenta is associated with high rate of maternal and fetal morbidity and mortality, Because of this association found between placental abruption and maternal and fetal morbidity and mortality, the conditions predisposing it should be carefully evaluated in order to reduce the occurrence of placental abruption.

Antenatal care which identifies the risk factors like PIH plays an important role in decreasing the incidence of abruptio placenta and improving the maternal and fetal outcome. Regular antenatal check-up, anemia correction, early diagnosis and identification of gestational hypertension would prevent the maternal and perinatal morbidity and mortality. Team efforts by obstetricians, intensivists, blood bank and neonatologist are required for better maternal and fetal outcome.

Funding: No funding sources

Conflict of interest: None declared

Ethical approval: The study was approved by the Institutional Ethics Committee

\section{REFERENCES}

1. Workalemahu T, Enquobahrie DA, Gelaye B, Thornton TA, Tekola-Ayele F, Sanchez SE, et al.
Abruptio placentae risk and genetic variations in mitochondrial biogenesis and oxidative phosphorylation: replication of a candidate gene association study. Am J Obstet Gynecol. 2018;219(6):617-e1.

2. Sylvester HC, Stringer M. Placental abruption leading to hysterectomy. Case Reports. 2017;2017.

3. Miller C, Grynspan D, Gaudet L, Ferretti E, Lawrence S, Moretti F, et al. Maternal and neonatal characteristics of a Canadian urban cohort receiving treatment for opioid use disorder during pregnancy. J Develop Orig Health Dis. 2019;10(1):132-7.

4. Ananth CV, Berkowitz GS, Savitz DA, Lapinski RH. Placental abruption and adverse perinatal outcomes. JAMA. 1999;282(17):1646-51.

5. Kayani SI, Walkinshaw SA, Preston C. Pregnancy outcome in severe placental abruption. BJOG: An Inter J Obstet Gynaecol. 2003;110(7):679-83.

6. Wasnik SK, Naiknaware SV. Antepartum hemorrhage: causes and its effects on mother and child: an evaluation. Obstet Gynecol Int J. 2015;3(1):00072.

7. Bhattacharya R, Ramesh AC. Pregnancy outcomes in placental abruption in a tertiary care centre in Karnataka. Asian Res J Gynaecol Obstet. 2019:1-6.

8. Bibi S, Ghaffar S, Pir MA, Yousfani S. Risk factors and clinical outcome of placental abruption: a retrospective analysis. Shock. 2009;22:20.

Cite this article as: Patel K, Bhatu J, Patel S. Study of maternal and perinatal outcome in abruptio placentae. Int J Reprod Contracept Obstet Gynecol 2020;9:1882-5. 